\title{
Perinatal mortality and neonatal survival in Avon: 1976-9
}

\author{
L M M MUTCH, N J BROWN, B D SPEIDEL, P M DUNN
}

\begin{abstract}
A study of perinatal and neonatal mortality figures for all 36810 infants born to Avon residents during 1976-9 reported by year of birth and in relation to birth weight, gestational age, and the presence of lethal malformation showed the need for reporting mortality data for normally formed infants weighing $1000 \mathrm{~g}$ or more at birth and for assessing perinatal morbidity as well as mortality when attempting to evaluate the standard of perinatal care and the resources required to provide for it.
\end{abstract}

\section{Introduction}

Perinatal mortality statistics are often used to reflect the quality of maternal and newborn care. The use of crude data, however, is often misleading. Most routinely collected population-based data lack sufficient detail to permit meaningful interpretation, while the more detailed type of analysis based on hospital studies usually lacks the numbers required for statistical validity and may be biased because of patient selection. This study of all births to women resident in Avon Area Health Authority over a four-year period was designed to avoid both these criticisms and to produce perinatal statistics more truly reflecting the quality of care.

\footnotetext{
Departments of Child Health, Paediatrics, and Pathology, Southmead Hospital and Bristol Maternity Hospital, Bristol

L M M MUTCH, MB, CHB, senior clinical medical officer

N J BROWN, FRCP, FRCPATH, consultant paediatric pathologist

B D SPEIDEL, MD, MRCP, consultant paediatrician

P M DUNN, MD, FRCP, reader in child health and perinatal medicine
}

\section{Case material and method}

The county of Avon, an area of 520 square miles (1341 sq km), was created in 1974 after the reorganisation of county boundaries. Avon Area Health Authority manages the county of Avon excluding the Bath Health District, which is administered by Wiltshire Area Health Authority. Avon area had an estimated managed population of 817300 in 1976, including 157300 women aged between 15 and 45 . About half the population live in the city of Bristol, while the remainder live in five small towns and in the surrounding rural area. The social class distribution of births in 1977 was not appreciably different from the rest of England and Wales: social classes I and II, $30.2 \%$; III, $47.8 \%$; IV and V, $19.8 \%$. The equivalent figures for England and Wales in that year were $27 \cdot 6 \%, 48 \%$, and $20.8 \%$. No recent information is available on ethnic distribution, but in 1971 $5.6 \%$ of births in Bristol City were to mothers whose own birthplace was outside Britain.

The distribution of births by place of delivery was as follows: $84.6 \%$ in Southmead Hospital and Bristol Maternity Hospital, each of which provides special and intensive baby care; $4.3 \%$ in Weston General Hospital, another consultant obstetric unit but without resident paediatric cover; $10.1 \%$ in general practitioner maternity units; and $1.0 \%$ at home or elsewhere.

Perinatal deaths were identified initially by a comparison of birth notification and death registration files. This was checked against other sources of information, such as hospital records including necropsy files, but these showed only one death that had not been previously registered. Clinical and pathological information was extracted from case records, including the standard Avon neonatal discharge record, and from necropsy reports where available. This was possible in every case except one-a home delivery after a concealed pregnancy that resulted in a stillbirth. A necropsy was performed, but unfortunately the records have been mislaid.

In this paper we have used the following definitions: stillbirth-an infant without signs of life born after the 28th week of gestation; neonatal death-the death of a liveborn infant within 28 days of birth irrespective of gestational age; perinatal deaths-stillbirths plus firstweek deaths; deaths due to lethal malformation-deaths associated with congenital malformation incompatible with life and to whom the administration of intensive neonatal care was considered inappropriate. Infants with a birth weight of less than $500 \mathrm{~g}$ have been excluded from this study.

There were 36810 births in Avon area over the four-year period 
(table I); in common with the national trend there was an initial fall in the number of births during 1976 and 1977 followed by a rise beginning at the end of 1978 . The number of births in 1979 was $7 \cdot 2 \%$ higher than in 1976 and $9.54 \%$ higher than in 1977 . There were 297 stillbirths and 299 neonatal deaths during the whole period (first-week deaths: 243). Necropsy was performed on $90 \cdot 2 \%$ of stillbirths, $69 \cdot 2 \%$ of neonatal deaths, and $81 \cdot 2 \%$ of all perinatal deaths. The necropsy rate for normally formed infants weighing $1000 \mathrm{~g}$ or more at birth and dying in the perinatal period was $86.8 \%$.

\section{Results}

The overall perinatal mortality rate for Avon area residents, 1976-9, was $14 \cdot 7$, the stillbirth rate $8 \cdot 1$, and the neonatal mortality rate $8 \cdot 2$. Table I shows the breakdown by year of birth.

TABLE I-Perinatal death rates of all infants, Avon residents 1976-9

\begin{tabular}{|c|c|c|c|c|c|c|}
\hline & & 1976 & 1977 & 1978 & 1979 & Total \\
\hline $\begin{array}{l}\text { No of births } \\
\text { Perinatal mortality rate } \\
\text { Stillbirth rate } \\
\text { Neonatal mortality rate... }\end{array}$ & $\begin{array}{l}\ldots \\
\because \\
\therefore\end{array}$ & $\begin{array}{r}9017 \\
15 \cdot 7 \\
8 \cdot 6 \\
8 \cdot 3\end{array}$ & $\begin{array}{r}8813 \\
15 \cdot 2 \\
8 \cdot 4 \\
8 \cdot 8\end{array}$ & $\begin{array}{r}9310 \\
14 \cdot 4 \\
8 \cdot 3 \\
7 \cdot 5\end{array}$ & $\begin{array}{r}9670 \\
13 \cdot 4 \\
7 \cdot 0 \\
8 \cdot 2\end{array}$ & $\begin{array}{r}36810 \\
14 \cdot 7 \\
8 \cdot 1 \\
8 \cdot 2\end{array}$ \\
\hline
\end{tabular}

Lethal malformation accounted for 184 of the 540 perinatal deaths (34.1\%), for 80 of the 297 stillbirths ( $26.9 \%$ ), and for 136 of the 299 neonatal deaths $(45.5 \%)$. If these malformed infants are excluded then the corrected perinatal mortality rate is $9 \cdot 7$, the stillbirth rate 5.9 , and the neonatal mortality rate 4.5 (table II). During the fouryear period 124 infants had a birth weight of less than $1000 \mathrm{~g} ; 109$ were either born dead or died in the neonatal period. These tiny infants, representing $0.34 \%$ of all live and stillbirths, accounted for $20.8 \%$ of all deaths. Among live births they formed $0.21 \%$ of the population, $21.0 \%$ of all neonatal deaths, and $33.9 \%$ of neonatal deaths among infants without lethal malformation. If these infants are excluded as well as those with lethal malformation the rates for perinatal mortality fall to $7 \cdot 3$, stillbirths to $5 \cdot 0$, and neonatal mortality to 2.9 (table III). The influence of both these factors on perinatal mortality rates is shown in fig 1.

TABLE II-Perinatal death rates of infants after excluding infants with letha malformation, Avon residents 1976-9

\begin{tabular}{|c|c|c|c|c|c|c|}
\hline & & 1976 & 1977 & 1978 & 1979 & Total \\
\hline $\begin{array}{l}\text { No of births } \\
\text { Perinatal mortality rate } \\
\text { Stillbirth rate } \\
\text { Neonatal mortality rate.. }\end{array}$ & $\begin{array}{l}\cdots \\
\cdots \\
\cdots\end{array}$ & $\begin{array}{r}8962 \\
10 \cdot 4 \\
6 \cdot 7 \\
4 \cdot 2\end{array}$ & $\begin{array}{r}8757 \\
9 \cdot 7 \\
5 \cdot 9 \\
4 \cdot 9\end{array}$ & $\begin{array}{r}9256 \\
9 \cdot 8 \\
6 \cdot 1 \\
3 \cdot 9\end{array}$ & $\begin{array}{r}9619 \\
8 \cdot 9 \\
5 \cdot 1 \\
4 \cdot 9\end{array}$ & $\begin{array}{r}36594 \\
9 \cdot 7 \\
5 \cdot 9 \\
4 \cdot 5\end{array}$ \\
\hline
\end{tabular}

TABLE III-Perinatal death rates of infants after excluding infants with lethal malformation and with birth weights of less than $1000 \mathrm{~g}$, Avon residents 1976-9

\begin{tabular}{|c|c|c|c|c|c|c|}
\hline & & 1976 & 1977 & 1978 & 1979 & Total \\
\hline $\begin{array}{l}\text { No of births } \\
\text { Perinatal mortality rate } \\
\text { Stillbirth rate } . \\
\text { Neonatal mortality rate.. }\end{array}$ & $\begin{array}{l}\ldots \\
\ldots\end{array}$ & $\begin{array}{r}8948 \\
9 \cdot 1 \\
5 \cdot 8 \\
3 \cdot 5\end{array}$ & $\begin{array}{r}8727 \\
6 \cdot 9 \\
4 \cdot 2 \\
3 \cdot 6\end{array}$ & $\begin{array}{r}9231 \\
7 \cdot 6 \\
5 \cdot 5 \\
2 \cdot 2\end{array}$ & $\begin{array}{r}9582 \\
5.9 \\
4.6 \\
2.4\end{array}$ & $\begin{array}{r}36488 \\
7 \cdot 3 \\
5 \cdot 0 \\
2 \cdot 9\end{array}$ \\
\hline
\end{tabular}

The distribution of births and deaths, and one-month survival of all 36377 liveborn infants whose birth weight was known and who weighed more than $500 \mathrm{~g}$ at birth (excluding lethal malformations) is shown in table IV and fig 2 in relation to birth weight groups. The neonatal mortality for normally formed infants weighing $2500 \mathrm{~g}$ or more at birth was 1.2 per 1000 live births. Figure 3 shows similar distributions and survival in relation to gestational age.

The incidence of low birth weight (less than $2500 \mathrm{~g}$ ) for the fouryear period was $6.4 \%$, the numbers born in each successive year being $545,560,616$, and 617 . These low-birthweight infants were associated with $59 \%, 66 \%, 65 \%$, and $71 \%$ of all stillbirths and neonatal deaths, the overall figure being $62.3 \%$, (table V). If infants with lethal malformation or with a birth weight below $1000 \mathrm{~g}$ are excluded then the remaining low-birthweight infants represent $5.8 \%$ of all births, and were associated with $59.8 \%$ of perinatal deaths, $50.8 \%$ of stillbirths, and $67.9 \%$ of neonatal deaths.
The incidence of infants of very low birth weight (less than $1500 \mathrm{~g}$ ) for the four-year period was $1.04 \%$, the numbers for each successive year being $77,92,102$, and 110 . These infants were associated with $31.4 \%, 38.8 \%, 38.2 \%$, and $41.4 \%$ of all stillbirths and neonatal deaths, the overall figure being $36.9 \%$. If infants with lethal malformation are excluded then the incidence of very low birth weight was $0.89 \%$, the figures for each successive year being $0.77 \%, 0.87 \%$, $0.9 \%$, and $1.0 \%$. They were associated with $39.8 \%$ of perinatal deaths, $36.0 \%$ of stillbirths, and $24.4 \%$ of neonatal deaths. The onemonth survival of liveborn infants for each successive year was $55.8 \%, 62.7 \%, 75.0 \%$, and $62.8 \%$, the overall figure being $62.5 \%$. If infants of $1000-1499 \mathrm{~g}$ are considered on their own then the onemonth survival for each year was $63.6 \%, 79.4 \%, 81 \cdot 1 \%$, and $85.4 \%$, the overall figure being $77 \cdot 1 \%$.

Among all infants dying in the neonatal period, $81 \%$ of deaths occurred in the first week of life, $46.6 \%$ of the deaths being on the first day. The proportion of infants dying in the neonatal period after the first week for each year was $14 \cdot 6 \%, 22 \cdot 1 \%, 17 \cdot 4 \%$, and $21.5 \%$ (average: $19.0 \%$ ). If infants of birth weight below $1000 \mathrm{~g}$ and

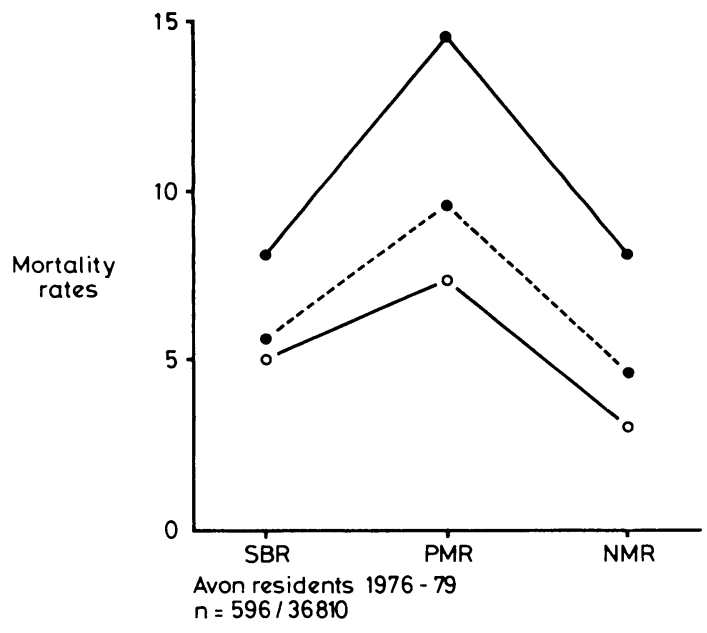

FIG 1-Stillbirth rates (SBR), perinatal mortality rates (PMR), and neonatal mortality rates (NMR) for Avon residents $(N=36810), 1976-9: \bullet-\square$ all infants;

- ------ excluding infants with lethal malformation; $\bigcirc-O$ excluding malformations and infants with birthweights less than $1000 \mathrm{~g}$.

TABLE IV-Distribution of births, deaths, and neonatal survival of liveborn infants by birth weight after excluding infants with lethal malformations, Avon residents, 1976-9

\begin{tabular}{|c|c|c|c|c|c|}
\hline \multirow{2}{*}{ Birth weight (g) } & \multicolumn{2}{|c|}{ Liveborn infants } & \multicolumn{2}{|c|}{ Neonatal deaths } & \multirow{2}{*}{$\begin{array}{c}\% \text { Neonatal } \\
\text { survival }\end{array}$} \\
\hline & No & $\%$ Distribution & No & $\%$ Distribution & \\
\hline $\begin{array}{c}500-999 \\
1000-1499 \\
1500-1999 \\
2000-2499 \\
2500-2999 \\
3000-3499 \\
3500-3999 \\
4000-4499 \\
>4500\end{array}$ & $\begin{array}{r}77 \\
179 \\
406 \\
1427 \\
6473 \\
14098 \\
10453 \\
2816 \\
387\end{array}$ & $\begin{array}{r}0.2 \\
0.5 \\
1 \cdot 1 \\
3.9 \\
17 \cdot 8 \\
38 \cdot 8 \\
28 \cdot 8 \\
.7 \cdot 8 \\
1.1\end{array}$ & $\begin{array}{r}56 \\
40 \\
19 \\
9 \\
13 \\
13 \\
10 \\
5 \\
0\end{array}$ & $\begin{array}{r}33 \cdot 9 \\
24 \cdot 2 \\
11.5 \\
5.5 \\
7.9 \\
7.9 \\
6 \cdot 1 \\
3.0 \\
-\end{array}$ & $\begin{array}{r}27 \cdot 3 \\
77 \cdot 1 \\
95 \cdot 3 \\
99 \cdot 4 \\
99 \cdot 8 \\
99 \cdot 9 \\
99 \cdot 9 \\
99 \cdot 8 \\
100 \cdot 0\end{array}$ \\
\hline Total & 36316 & $100 \%$ & 165 & $100 \%$ & Mean 99.5 \\
\hline
\end{tabular}

TABLE v-Percentage of low-birthweight infants, Avon residents 1976-9

\begin{tabular}{|c|c|c|c|c|c|c|}
\hline & \multicolumn{2}{|c|}{ Weight (g) } & \multirow{2}{*}{$\begin{array}{l}\text { Total } \\
<1500\end{array}$} & \multicolumn{2}{|c|}{ Weight (g) } & \multirow{2}{*}{$\begin{array}{r}\text { Total } \\
<2500\end{array}$} \\
\hline & $500-$ & $1000-$ & & 1500 & $2000-$ & \\
\hline \multirow{4}{*}{$\begin{array}{l}\text { All births }(\%) \quad \ldots \\
\text { All perinatal } \\
\text { deaths }(\%) \\
\text { One-month survival of } \\
\text { liveborn infants }(\%) \\
\text { One-month survival of } \\
\text { liveborn infants } \\
\text { excluding lethal } \\
\text { malformations }(\%)\end{array}$} & 0.3 & 0.7 & $1 \cdot 0$ & $1 \cdot 3$ & $4 \cdot 1$ & $6 \cdot 4$ \\
\hline & $17 \cdot 1$ & $19 \cdot 8$ & $36 \cdot 9$ & $13 \cdot 6$ & 11.9 & $62 \cdot 3$ \\
\hline & $26 \cdot 8$ & $72 \cdot 4$ & $58 \cdot 8$ & 91.9 & $97 \cdot 6$ & 91.5 \\
\hline & $27 \cdot 3$ & $77 \cdot 1$ & $62 \cdot 5$ & $95 \cdot 1$ & $99 \cdot 3$ & 93.9 \\
\hline
\end{tabular}

*Includes all neonatal deaths. 


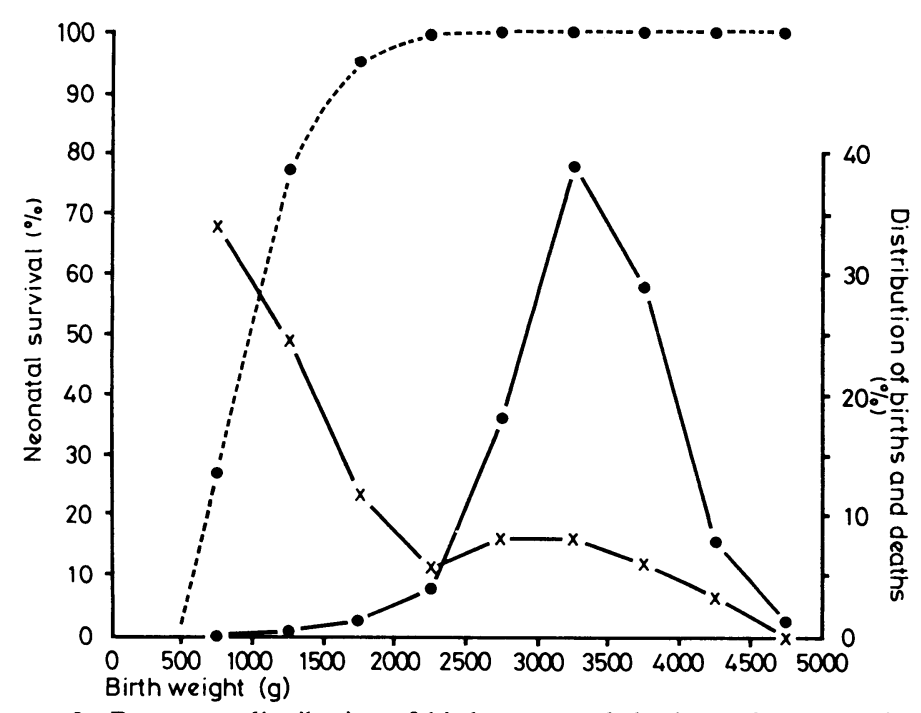

FIG 2-Percentage distribution of births, neonatal deaths, and one-month survival of normally formed liveborn infants delivered to Avon residents, $1976-9$ in relation to birthweight groups $(N=36377): \bullet-\bullet$ distribution of births; X $\mathrm{X}$ distribution of deaths; -...-. neonatal survival.

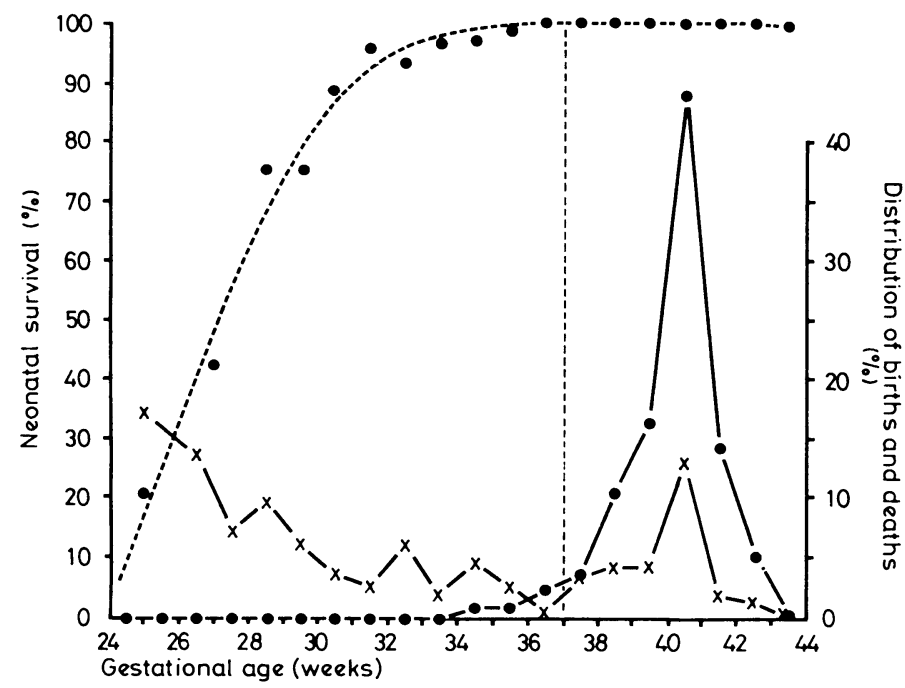

FIG 3-Percentage distribution of births, neonatal deaths, and one-month survival of normally formed liveborn infants delivered to Avon residents, 1976-9 in relation to gestational age: ——— distribution of births; $\mathrm{X}-\mathrm{X}$ distribution of deaths; ---.-- $\bullet$ neonatal survival.

those with lethal malformation are excluded then $78.3 \%$ of deaths occurred in the first week, with $42.3 \%$ on the first day of life. Threequarters of the first-day deaths occurred within 12 hours of birth. The proportion of late neonatal deaths for each year among such infants was $12.5 \%, 29.0^{\circ}, 4.5 \%$, and $38.5 \%$ (average $21.6^{\circ} \%$ ).

\section{Discussion}

If death rates in the perinatal period are to be used to reflect the standard of perinatal care they should be based on the population and must include information on birth weight and preferably also on gestational age. Accurate information on the incidence of deaths due to malformation is also essential as the salvage of such babies may be neither possible nor desirable. To achieve this a high necropsy rate is necessary. The importance of providing data on these subjects rests partially on the fact that most perinatal deaths are associated with either low birth weight or malformation, and partially because the incidence of both are known to vary considerably among and also within different countries. ${ }^{1}$ Some of these points are well illustrated in the present study. For example, $58.1 \%$ of neonatal deaths among normally formed infants occurred among the $0.7 \%$ of liveborn infants whose birth weight was below $1500 \mathrm{~g}$ (table IV). Likewise, $37.9 \%$ of deaths among normal liveborn infants occurred among the $0.3 \%$ of infants having a gestational age of less than 28 weeks (fig 3). Again, congenital malformation accounted for $34.1 \%$ of all perinatal deaths in our study, a figure that incidentally is considerably higher than the $26 \%$ reported for Scotland in $1977^{2}$ and the recent $27 \%$ estimate for England. ${ }^{3}$ To take a further example, if the death rates for births to Avon area residents in 1979 are compared with those in 1976 we find that the rates for stillbirths fell by $18.6 \%$, perinatal mortality by $10.8 \%$, and neonatal mortality by only $1 \cdot 2 \%$. If, however, infants with lethal malformations and those with a birth weight below $1000 \mathrm{~g}$ are excluded then the rates for stillbirths fell by $20 \cdot 7 \%$, perinatal mortality by $35.2 \%$, and neonatal mortality by $31.4 \%$ (fig 1 ). Without this more detailed analysis, it might have appeared that there had been no appreciable improvement in neonatal outcome over the four-year period, whereas in fact the survival of "salvagable" infants had greatly increased. These findings confirm the wisdom of the recommendation by the British Paediatric Association/ Royal College of Obstetricians and Gynaecologists' Liaison Committee $^{4}$ that in future all perinatal mortality statistics should be subdivided into at least three groups: infants with lethal malformations, infants weighing less than $1000 \mathrm{~g}$ at birth, and infants without lethal malformation weighing more than $1000 \mathrm{~g}$ at birth.

Chalmers and Macfarlane ${ }^{1}$ have pointed out that paediatric techniques may prolong life beyond the first week, producing a shift of perinatal mortality into the late neonatal period. The Avon data does suggest a trend in this direction but the numbers are small, and about $80 \%$ of neonatal deaths continue to take place within one week of birth. Another factor that influences the perinatal mortality rate is the local policy with respect to prenatal diagnosis and abortion of infants with severe malformation and also the management of such infants when born alive. This point further emphasises the importance of providing separate mortality statistics for normally formed infants and also for including the whole neonatal period in reported results. The distribution of births and deaths and one-month survival of normally formed infants in relation to birth weight (fig 2) and gestational age (fig 3 ) highlights the importance of providing neonatal intensive care facilities for infants of extreme prematurity and very low birth weight. ${ }^{2-4}$ That such a high proportion of neonatal deaths occurs within hours of birth reinforces the need for expert resuscitative care at this critical time of life. ${ }^{3}$

The development of neonatal intensive care during the past decade has increasingly permitted the obstetrician to rescue the endangered fetus by premature delivery. Whereas in the 1960 s elective delivery was rarely undertaken before 34 weeks' gestation it has now become accepted obstetric practice in many areas to deliver infants at risk of dying as early as $26-28$ weeks. As a result some fetuses that would have previously been aborted or stillborn are now born alive but premature. While this changing policy is likely to contribute to a fall in the stillbirth rate, it is at the same time likely to lead to an increase in lowbirthweight infants and to a rise in neonatal mortality. Between 1976 and 1979 there was a $13.2 \%$ increase in low-birthweight infants in Avon area as compared with an overall $7 \cdot 2 \%$ rise in the birth rate. Contrary to the experience of Gordon ${ }^{5}$ in Sheffield, who reported a fall in the incidence of very lowbirthweight infants, in Avon area this was the very group in which the greatest increase was noted-the number of liveborn infants without lethal malformation weighing less than $1500 \mathrm{~g}$ increased by $50 \%$ between 1976 and 1979, whereas the total number of infants born alive without lethal malformation increased by only $7 \cdot 5 \%$. With improving neonatal intensive care the one-month survival of such infants also greatly increased 
over the four years, more than doubling for infants weighing less than $1000 \mathrm{~g}$ and rising from $63.6 \%$ to $85.4 \%$ for infants of $1000-1500 \mathrm{~g}$. As such infants usually require several weeks of intensive care, the impact of these two trends is bound to lead to a very great additional burden on the slender neonatal facilities currently available. ${ }^{2-4}$ These observations also underline the importance of assessing perinatal morbidity as well as mortality when attempting to evaluate the standard of perinatal care and the resources required to provide for it.

We thank our many colleagues in obstetrics, midwifery, and general practice; Avon Area Health Authority for their support, and in particular Mr D Simpson, systems analyst, for his help.

Reprints requests should be addressed to: Dr P M Dunn, Southmead Hospital, Bristol.

\section{References}

${ }^{1}$ Chalmers I, Macfarlane A. In: Wharton B, ed. Topics in perinatal medicine. London: Pitman Medical, 1980:1-11.

${ }^{2}$ McIlwaine GM, Howat RCL, Dunn F, MacNaughton MC. Scotland 1977 perinatal mortality survey. Glasgow: Department of Obstetrics and Gynaecology, University of Glasgow, 1979.

${ }^{3}$ Social Services Committee, House of Commons. Perinatal and neonatal mortality. 2nd report. Volume 1. London: HMSO, 1980:32,106. (Chairman: Mrs Renee Short.)

${ }^{4}$ British Paediatric Association/Royal College of Obstetricians and Gynaecologists' Liaison Committee. Recommendations for the improvement of infant care during the perinatal period in the United Kingdom. London: BPA/RCOG, 1978. (Discussion document.)

${ }^{5}$ Gordon RR. Disproportion in the falling birth rate. $\mathrm{Br}$ Med $\mathcal{F} 1977$;ii : 939-40.

(Accepted 23 October 1980)

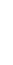

\section{赵}

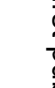

